This item was submitted to Loughborough's Research Repository by the author.

Items in Figshare are protected by copyright, with all rights reserved, unless otherwise indicated.

\title{
Economic activity, credit market conditions and the housing market
}

PLEASE CITE THE PUBLISHED VERSION

https://doi.org/10.1017/S1365100516000869

PUBLISHER

(C) Cambridge University Press (CUP)

\section{VERSION}

AM (Accepted Manuscript)

\section{PUBLISHER STATEMENT}

This work is made available according to the conditions of the Creative Commons Attribution-NonCommercialNoDerivatives 4.0 International (CC BY-NC-ND 4.0) licence. Full details of this licence are available at: https://creativecommons.org/licenses/by-nc-nd/4.0/

\section{LICENCE}

CC BY-NC-ND 4.0

\section{REPOSITORY RECORD}

Agnello, Luca, Vitor Castro, and Ricardo M. Sousa. 2019. "Economic Activity, Credit Market Conditions and the Housing Market". figshare. https://hdl.handle.net/2134/24140. 


\title{
Economic Activity, Credit Market Conditions and the Housing Market*
}

\author{
Luca Agnello ${ }^{\dagger}$ \\ University of Palermo
}

\author{
Vitor Castro C $^{\ddagger}$ \\ University of Coimbra and NIPE
}

\begin{abstract}
In this paper, we assess the characteristics of the housing market and its main determinants. Using data for 20 industrial countries over the period 1970Q1-2012Q2 and a discrete-time Weibull duration model, we find that the likelihood of the end of a housing boom or a housing bust increases over time. Additionally, we show that the different phases of the housing market cycle are strongly dependent on the economic activity, but credit market conditions are particularly important in the case of housing booms. The empirical findings also indicate that while housing booms have similar length in European and non-European countries, housing busts are typically shorter in European countries. The use of a more flexible specification for the hazard function that is based on cubic splines suggests that it evolves in a nonlinear way. From a policy perspective, our study can be useful for predicting the timing and the length of housing boom-bust cycles. Moreover, it highlights the importance of monetary policy by influencing lending rates and affecting the likelihood of occurrence of housing booms.
\end{abstract}

Keywords: housing booms and busts, duration analysis, Weibull model, duration dependence, cubic splines.

JEL Classification: C41, E32, E51, E52.

\footnotetext{
${ }^{*}$ We are grateful to participants to the 2nd International Workshop on "Financial Markets and Nonlinear Dynamics" (FMND), organized in Paris on June 4-5, 2015 (http://www.fmnd.fr), the Guest Editor, Fredj Jawadi, and Philip Rothman for their constructive comments and suggestions that considerably improved this paper. Castro and Sousa acknowledge that this work has been financed by Operational Programme for Competitiveness Factors - COMPETE and by National Funds through the FCT - Portuguese Foundation for Science and Technology within the remit of the project "FCOMP-01-0124-FEDER-037268 (PEst-C/EGE/UI3182/2013)".

${ }^{\dagger}$ University of Palermo, Department of Economics, Business and Statistics (SEAS), Viale delle Scienze, 90128 Palermo, Italy. Email: luca.agnello01@economia.unipa.it.

${ }^{\ddagger}$ University of Coimbra, Faculty of Economics, Av. Dias da Silva, 165, 3004-512 - Coimbra, Portugal; University of Minho, Economic Policies Research Unit (NIPE), Campus of Gualtar, 4710-057 - Braga, Portugal. Email: vcastro@fe.uc.pt.

$\S$ University of Minho, Department of Economics and Economic Policies Research Unit (NIPE), Campus of Gualtar, 4710-057 - Braga, Portugal; London School of Economics, LSE Alumni Association, Houghton Street, London WC2 2AE, United Kingdom. Emails: rjsousa@eeg.uminho.pt, rjsousa@alumni.lse.ac.uk.
} 


\section{Introduction}

The economic damages associated with the global financial crisis of 2008-2009 have quickly raised calls from policy makers around the world to deal with the need to promote the private sector deleveraging process and, simultaneously, to intensify the implementation of stimuli measures aimed at boosting the economy and strengthening the recovery. Not surprisingly, these developments have revived the research interest about the behaviour of the housing market and the business cycle desynchronization that followed after the financial turmoil (Mallick and Mohsin, 2007, 2010), the macroeconomic determinants of the housing boom-bust cycles (Agnello and Schuknecht, 2011), the nexus between monetary stability and financial stability (Sousa, 2010a), and, more generally, the linkages between the housing sector, the financial markets and the real economic activity (Jawadi, 2008; Arghyrou, 2009; Sousa, 2010b; Arghyrou and Tsoukalas, 2011; Jawadi and Léoni, 2012).

Given the severity and persistence of the Great Recession, understanding the characteristics of the various phases of the housing market cycle and their key drivers becomes crucial. Thus, the objective of this paper is threefold. First, we assess whether the end of a housing boom, a housing bust or a normal time spell depends on its own age. Second, we investigate how economic and credit market developments contribute to the duration of the housing market cycle. Third, we explore how those phases differ between European and non-European countries.

To address these questions, we use quarterly data over the period 1970-2012 for a group of 20 industrialized countries. After identifying the various phases of the housing market cycle via the detection of upturns and downturns in real housing prices, we estimate a discrete-time Weibull duration model to investigate the presence of duration dependence in housing booms, housing busts and normal times. The inclusion of a set of time-varying covariates in the model allows us to formally test for the importance of the state of the economy and credit market conditions in determining the length of housing market cycles.

Our empirical findings can be summarized as follows. First, we find that the probability of the end of a housing boom and a housing bust increases as these episodes become older, i.e. as time goes by. In contrast, normal time spells do not display duration dependence. Second, our results show that the housing market cycles are largely influenced by real economic activity. Lending rates are also important determinants of the duration of housing booms. Third, we find that while there are not significant differences in the duration of housing booms between European and nonEuropean countries, housing busts tend to be longer in non-European countries. Finally, using a more flexible splines variables-based approach to model the hazard function, we observe that it exhibits a nonlinear shape even though it keeps increasing over time.

The rest of the paper is organized as follows. In Section 2, we review the related literature. In Section 3, we present the econometric framework. In Section 4, we describe the data and discuss the empirical results. Finally, in Section 5, we conclude and draw the main policy implications.

\section{Review of the Literature}

The link between the housing market developments and the macroeconomy has been extensively explored for major industrialized countries. Regional or cross-country studies have typically 
found that housing prices are strongly influenced by business cycle fluctuations, being driven by fundamentals such as income growth, industrial production and employment rate (Hwang and Quigley, 2006). Others have highlighted the importance of financial variables, such as the interest rate and the monetary aggregates or the availability of credit (Agnello and Schuknecht, 2011). In spite of this, it is still difficult to find a consensus about the causes of the housing market fluctuations. For instance, in the case of the US, the application of the static asset market approach to the case of housing valuation suggests that the fall of real long-term interest rates during housing booms is regarded as an important determinant of house prices (Poterba, 1984). In contrast, accounting for credit-constrained home buyers, elastic housing supply, mean-reverting interest rates, mobility and prepayment, the generalization of the standard user-cost model to housing prices shows that interest rates do not influence house prices in a significant manner and lower real interest rates only explain one-fifth of the rise in housing prices from 1996 to 2006 (Glaeser et al., 2010).

Some pieces of research have also focused on the driving forces of the occurrence of episodes of booms and busts in asset markets. For instance, Agnello and Schucknecht (2011) look at the characteristics of housing booms and busts for a sample of eighteen industrialized countries over the period 1980-2007. They uncover a significant influence of domestic credit and interest rates on the frequency of such episodes. Interestingly, the authors also find that international liquidity is prone at leading to housing booms, while banking crises are likely to generate housing busts.

In this context, the duration analysis emerges as an important tool at providing some light to the issue. Having been employed in labour economics to assess the duration of spells of unemployment (Allison, 1982) and, more recently, to analyze the duration of the business cycles phases (Zuehlke, 2003; Castro, 2010, 2013) and the duration of fiscal consolidation programmes (Agnello et al., 2013), this framework can be extremely useful at assessing the duration of housing market cycles. ${ }^{1}$

The seminal work of Zuehlke (1987) paved the ground for further development in this area. The author uses a Weibull hazard model to analyze the link between the probability of sale and the market duration in housing markets. He shows that while vacant houses display positive duration dependence, such evidence is not found for occupied houses. This result is in line with the existence of stronger incentives for adopting diminishing reservation prices (or, putting it differently, a higher opportunity cost) in the case of the owners of a vacant house, thereby, implying that vacant houses have a higher rate of time dependence than occupied houses. Payne and Zuehlke (2006) apply hazard models to test for duration dependence in the market for real estate investment trusts. By focusing on information about the length of time between turning points of the cycle, the authors find evidence of duration dependence. As a result, hazard models provide a relatively robust way of predicting the timing of mean reversion of the housing market indices.

We try to improve upon the existing literature in several directions. First, the identification of the various stages of the housing market cycles for a large number of countries and over a long time span allow us to provide a comprehensive analysis of housing booms, housing busts and normal time spells from an international perspective. Second, we rely on a discrete-time Weibull model to test for the presence of duration dependence and to assess the impact of time-varying factors (such as, economic activity and credit market conditions) on the duration of the different

\footnotetext{
${ }^{1}$ Rothman (1996) also provides international evidence of nonlinearity in the business cycle dynamics.
} 
phases of the housing market cycle. This represents an improvement vis-a-vis the work of Agnello et al. (2015), who focus instead on the continuous-time Weibull model. Indeed, this framework is somewhat restrictive, as it only allows for the inclusion of time-invariant regressors. Third, we employ flexible cubic-splines specifications for the hazard function. Apart from granting more flexibility in terms of modelling, it makes it possible for us to evaluate the extent to which the hazard function may exhibit some nonlinearity over time. The possibility of nonlinearity in the hazard function has been documented by the work of Zuehlke (2013) and, more recently, in Agnello et al. (2015), who account for the existence of a change-points in the hazard function by extending the baseline continuous-time (Weibull) model to the duration of periods of booms, busts and normal times in the housing markets. ${ }^{2}$ Fourth, we rely on a database for a group of 20 industrialized countries over the period 1970Q1-2012Q2. This allows us to be able to compare the duration of the various phases of housing market cycles between European and Non-European countries, as well as understand their major determinants. Finally, from a policy perspective, our work can provide valuable information for predicting the timing and the length of housing boom-bust cycles, thereby, facilitating the formulation and the implementation of stabilizing policies (Mallick and Mohsin, 2010; Sousa, 2010a; Castro, 2011; Agnello et al., 2012; Castro and Sousa, 2012). To do it, we follow the general model framework developed by Castro (2013).

\section{Duration Models}

The duration variable is defined as the number of periods - quarters in this study - over which a housing market boom, bust or normal cycle takes place. If $T$ is defined as the discrete random variable that measures the time span between the beginning of one of those events and the moment it ends, the series of data at our disposal $\left(t_{1}, t_{2}, \ldots, t_{n}\right)$ will represent the duration of those events. The probability distribution of the duration variable $T$ can be specified by the cumulative distribution function $F(t)=\operatorname{Pr}(T<t)$. This function measures the probability of the random variable $T$ being smaller than a certain value $t$. The corresponding density function is then $f(t)=d F(t) / d t$. An alternative function for the distribution of $T$ is the survivor function, $S(t)=\operatorname{Pr}(T \geq t)=1-F(t)$. This function measures the probability of the duration of an event being greater than or equal to $t$. A particularly useful function for duration analysis is the hazard function $h(t)=f(t) / S(t)$, which measures the rate at which housing booms, busts or normal times will end at $t$, given that they lasted until that moment. In other words, it captures the probability of exiting from a state in moment $t$ conditional on the length of time in that state. From the hazard function, we can derive the integrated hazard function $H(t)=\int_{0}^{t} h(u) d u$, and compute the survivor function as $S(t)=\exp [-H(t)]$. The hazard function allows for a characterization of the dependence duration path. If $d h(t) / d t>0$ when $t=t^{*}$, there is positive duration dependence in $t^{*}$, that is, the probability of a housing boom, bust or normal time ending at $t$, given that it has reached $t$, increases with its age. Thus, the longer the respective event is, the higher the conditional probability of it ending will be.

Several parametric countinuous-time duration models can be proposed to measure the magni-

\footnotetext{
${ }^{2}$ More generally, for a review of the topic of nonlinearity in economic and financial time-series and the study of structural changes in macroeconomic time-series, see Rothman (1999, 2006).
} 
tude of the duration dependence and the impact of other time-invarying variables on the likelihood of an event ending, but the functional form that has been mostly employed to parameterize the hazard function is the proportional hazards model $h(t, \mathbf{x})=h_{0}(t) \exp \left(\boldsymbol{\beta}^{\prime} \mathbf{x}\right){ }^{3}$ where $h_{0}(t)$ is the baseline hazard function that captures the duration dependence of the data, $\boldsymbol{\beta}$ is a $(K \times 1)$ vector of parameters to be estimated and $\mathbf{x}$ is a vector of covariates that do not vary over the duration of the event. This model can be estimated without imposing any specific functional form on the baseline hazard function, which leads to the so-called Cox model. However, this procedure is not adequate when we are studying duration dependence. An alternative estimation imposes one specific parametric form for the function $h_{0}(t)$, the most popular being the Weibull model. In this case, the (baseline) hazard function can be characterized as $h_{0}(t)=\gamma p t^{p-1}$, where $\gamma$ is a positive constant and $p$ parameterizes the duration dependence and is also positive. If $p>1$, the conditional probability of a turning point occurring increases as the phase gets older, i.e. there is positive duration dependence; if $p<1$ there is negative duration dependence; finally, if $p=1$, there is no duration dependence. In this last case, the Weibull model is equal to an Exponential model. Therefore, by estimating $p$, we can test for duration dependence in housing booms, busts and normal times.

Including the Weibull specification for the baseline hazard function in the proportional hazard function, we have:

$$
h(t, \mathbf{x})=\gamma p t^{p-1} \exp \left(\boldsymbol{\beta}^{\prime} \mathbf{x}\right) .
$$

Hence, the corresponding survival function is $S(t, \mathbf{x})=\exp [-H(t, \mathbf{x})]=\exp \left[-\gamma t^{p} \exp \left(\boldsymbol{\beta}^{\prime} \mathbf{x}\right)\right]$. This model can be estimated by Maximum Likelihood. The likelihood function for a sample of $i=$ $1, \ldots, n$ spells is given by $L(\cdot)=\prod_{i=1}^{n} f\left(t_{i}, \mathbf{x}_{i}\right)=\prod_{i=1}^{n} h\left(t_{i}, \mathbf{x}_{i}\right)^{c_{i}} S\left(t_{i}, \mathbf{x}_{i}\right)$, where $c_{i}$ indicates when observations are censored. If the sample period under analysis ends before the turning point has been observed, they will be censored $\left(c_{i}=0\right)$; if the turning points are observed in the sample period, they will not censored $\left(c_{i}=1\right)$.

Following Allison (1982), the corresponding log-likelihood function can be written as $\ln L(\cdot)=$ $\sum_{i=1}^{n}\left[c_{i} \ln h\left(t_{i}, \mathbf{x}_{i}\right)+\ln S\left(t_{i}, \mathbf{x}_{i}\right)\right]$ or, making use of the respective Weibull hazard and survival functions $\ln L(\cdot)=\sum_{i=1}^{n}\left[c_{i}\left(\ln \gamma+\ln p+(p-1) \ln t_{i}+\boldsymbol{\beta}^{\prime} \mathbf{x}_{i}\right)-\gamma t_{i}^{p} \exp \left(\boldsymbol{\beta}^{\prime} \mathbf{x}_{i}\right)\right]$. Theoretically, this is the basic structure of the log-likelihood function for the Weibull model that might be estimated to detect the presence of duration dependence in housing booms, busts or normal times. However, from an empirical point of view, this is not the most adequate model to employ because, although the duration of a housing boom, a housing bust or a normal time spell is a continuous-time process, the available data is inherently discrete. Allison $(1982$, p.70) states that when those “... discrete units are very small, relative to the rate of event occurrence, it is usually acceptable to ignore the discreteness and treat time as if it was measured continuously. [However,] when the time units are very large - months, quarters or years - this treatment becomes problematic...". This may be particularly relevant in the case of housing market cycles, where the available data is grouped into large (quarterly) discrete-time intervals. Therefore, the discrete-time duration analysis may be considered more effective than the continuous-time duration frameworks. Additionally, discrete-time

\footnotetext{
${ }^{3}$ This means that the ratio of the hazard rates for any pair of observations is constant over time.
} 
duration models have the advantage of easing the inclusion of time-varying covariates. Disregarding them could lead to biased estimates of the true duration dependence parameter (Jenkins, 1995).

To implement discrete-time methods, we can start with a continuous-time model - the proportional hazards model is a sensible choice - and, then, derive the appropriate estimator for data grouped into intervals. A discrete-time (grouped data) version of the proportional hazards model was developed by Prentice and Gloeckler (1978), Allison (1982) and Jenkins (1995). First, it is assumed that time can only take integer values $(t=1,2,3, \ldots)$ and that we observe $n$ independent spells (housing booms, busts or normal times) $(i=1,2, \ldots, n)$ starting at $t=1$. The observation continues until time $t_{i}$, at which either an event occurs or the observation is censored, i.e. the event is observed at $t_{i}$, but not at $t_{i+1}$. A vector of time-varying explanatory variables $\mathbf{x}_{i t}$ is also observed. Therefore, the discrete-time hazard rate can be defined as $P_{i t}=\operatorname{Pr}\left[T_{i}=t \mid T_{i}>t, \mathbf{x}_{i t}\right]$, where $T_{i}$ is the discrete random variable representing the uncensored time at which the event (boom, bust or normal time) ends. Consequently, $P_{i t}$ measures the conditional probability of event $i$ ending at time $t$, given that it has not ended yet. Assuming that the data is generated by the continuous-time proportional hazard model, Prentice and Gloeckler (1978) show that the corresponding discrete-time proportional hazard function can be expressed as

$$
P_{i t}=1-\exp \left[-h_{t} \exp \left(\boldsymbol{\beta}^{\prime} \mathbf{x}_{i t}\right)\right]=1-\exp \left[-\exp \left(\theta_{t}+\boldsymbol{\beta}^{\prime} \mathbf{x}_{i t}\right)\right]
$$

which is equivalent to the so-called complementary log-log (or cloglog) function $\ln \left[-\ln \left(1-P_{i t}\right)\right]=$ $\theta_{t}+\boldsymbol{\beta}^{\prime} \mathbf{x}_{i t}$, where $\theta_{t}\left(=\ln h_{t}\right)$ represents the logarithm of an unspecified (baseline hazard) function of time, $\mathbf{x}_{i t}$ is a vector of time-varying explanatory variables and the vector of coefficients $\boldsymbol{\beta}$ is identical to the one in the continuous-time proportional hazards model. This means that the continuous-time and discrete-time models will provide estimates of the same parameter, assuming that a proper interval for the observations is chosen. This, in turn, is set in such a way that the actual values of the covariates are constant over the interval.

In order to proceed with the estimation of the model, one needs to specify $\theta_{t}$. One suitable and quite popular functional form for $\theta_{t}$ is the discrete-time analogue to the Weibull model, which yields $\theta_{t}=\ln h_{t}=\alpha+(p-1) \ln t$. Following Prentice and Gloeckler (1978) and Allison (1982), the discrete-time $\log$-likelihood function for a sample of $i=1, \ldots, n$ spells can be written as

$$
\ln L(\cdot)=\sum_{i=1}^{n} \sum_{j=1}^{t_{i}} y_{i t} \ln \left(\frac{P_{i j}}{1-P_{i j}}\right)+\sum_{i=1}^{n} \sum_{j=1}^{t_{i}} \ln \left(1-P_{i j}\right),
$$

where the dummy variable $y_{i t}$ is equal to 1 if the housing boom, bust or normal time $i$ ends at time $t$, and 0 otherwise. Hence, this function is just the log-likelihood function for the regression analysis of binary dependent variables. Plugging the equation of the complementary log-log (or cloglog) function into the discrete-time log-likelihood function and using the adequate specification for the baseline hazard function, one can estimate the model by Maximum Likelihood. 


\section{Empirical Analysis}

\subsection{Data}

Quarterly data on the housing prices index (HPI) are provided by the Organisation for Economic Co-Operation and Development (OECD) and cover a sample of 20 industrialized countries over the period 1970Q1-2012Q2. ${ }^{4}$ Similarly to Agnello and Schuknecht (2011), the episodes of booms and busts in housing markets are identified using a statistical methodology. This requires the preliminary detection of upturns and downturns in real housing prices. To avoid capturing high-frequency changes, we first smooth the housing prices series. ${ }^{5}$

By organizing the quarterly data in spells where a spell represents the duration of a boom, a bust or a normal period, denoted by Dur, we are able to identify 59 booms, 31 busts and 59 normal time spells. ${ }^{6}$ The majority of the countries experienced booms and busts and, in most of the cases, boom-bust cycles. Moreover, a large group of countries including Denmark, France, Italy, Sweden and UK can be labelled as "repeated boom busters". Another group of countries can be defined as "new busters", as they were hardly hit by the sub-prime mortgage crisis. While this was initially confined to the US, it quickly spilled over the European housing markets, affecting countries such as Greece, Ireland, Netherlands and Spain, which recorded the most severe bust episodes in the Summer of 2007 and the beginning of 2008. The recent drawn-out bust seems to be relatively muted only in Belgium, Norway and Switzerland (the "resilient league").

Although the main goal of our paper is to test for the presence of duration dependence in housing booms, bust and normal times, an additional objective is to evaluate whether and how the economic environment affects their length. To proceed with such task, we use some economic variables (sourced from the International Financial Statistics (IFS) of the International Monetary Fund (IMF)) as regressors in this duration analysis.

According to Hwang and Quigley (2006) and Agnello and Schucknecht (2011), the state of the economy - in particular the evolution of GDP growth and industrial production - influences significantly the housing market and, thus, the duration of the housing market cycles. Therefore, we include in our estimations the growth rate of real GDP $(G D P)$ or the growth rate of the industrial production $(I P)$. In particular, we expect that a higher growth rate increases the length of housing booms and fastens the end of housing busts.

\footnotetext{
${ }^{4}$ The countries included in our sample are: Australia, Belgium, Canada, Denmark, Finland, France, Germany, Greece, Ireland, Italy, Japan, Korea, Netherlands, New Zealand, Norway, Spain, Sweden, Switzerland, the United Kingdom, and the United States.

${ }^{5}$ Let $y_{t}$ denote the logarithm of real housing prices and $x_{t}$ the centered-moving average of $y_{t}$, that is, $x_{t}=\frac{\sum_{j=-n}^{n} y_{t+j}}{2 n}$. An upturn is defined as an interval of time during which $\Delta x_{t}>0$ for all $t$, while a downturn is an interval of time in which $\Delta x_{t}<0$. A peak or trough is the last time period within an upturn and downturn, respectively. It follows that a housing boom is defined as an upturn such that $y_{T}-y_{T-L}>z$ and, analogously, a housing bust is a downturn for which $y_{T}-y_{T-L}<-z$, where $T$ indicates the peak of the boom or the trough of the bust and $L$ is the duration of the upturn or the downturn. The identification of booms and busts is based on the assumption that $n=5$ and $z=0.15$. For robustness check, we have also assumed different values of $z$ for booms and busts, respectively. More specifically $z$ has been set equal to the average size of upturns and downturns over the entire sample of analysis. Following this rule, boom and bust episodes occur when $y_{T}-y_{T-L}>0.23$ and $y_{T}-y_{T-L}<-0.11$, respectively. The results remain qualitatively and quantitatively unchanged and are available upon request.

${ }^{6}$ For brevity, the identified boom and bust episodes are not reported in the paper. However, they are available upon request.
} 
Other authors emphasize the importance of financial variables, such as the interest rate and the monetary aggregates (Agnello and Schucknecht, 2011). To test for their influence on the duration of housing cycles, we use the lending interest rate $($ LendIR) or the money market interest rate $(M M I R)$ as explanatory variables. We expect that higher interest rates are associated with shorter housing booms and longer housing busts.

The availability of credit is another important conditioning variable of the housing market (Agnello and Schucknecht, 2011). Hence, the duration of housing booms and busts may be influenced by an easing or a tightening of credit market conditions. To control for potential "credit effects", we include the growth rate of domestic credit $(\mathrm{Cred})$ or the ratio of domestic credit to GDP $($ CredGDP) in the model. We expect that when the available amount of credit increases, housing booms tend to be longer and housing busts are more likely to be shorter.

Finally, we also consider a dummy variable (European) to test whether housing booms/busts are longer (or shorter) in European countries than in non-European countries.

\subsection{Housing booms}

Tables 1 to 3 present estimates of a discrete-time Cloglog duration model. For each estimation - apart from the estimated coefficients and the corresponding robust standard errors -, we present the value of the $\log$-likelihood function $(\log L)$, the Akaike Information Criterion $(A I C)$, the Schwarz Bayesian Information Criterion $(S B I C)$, the Likelihood Ratio Index $(L R I)$, the number of observations and the number of ended spells.

Table 1 reports the results for housing booms. Column 1 reports estimates of the baseline model over the entire sample. In Column 2(3), only European (non-European) countries are considered in the sample. In Column 4, we restrict the sample to the period before the recent financial crisis (i.e. before 2008). To begin with, we consider the following specification for the logarithm of the baseline hazard function in the discrete-time cloglog model: $\theta_{t}=\alpha+(p-1) \ln t$, where $t$ measures the duration of a housing boom, i.e. $t=$ Dur. Regardless of the sample selection, the estimates of the duration dependence parameter $(p)$ suggest the existence of positive duration dependence, as $p$ is statistically greater than 1 . Moreover, the second derivative of the baseline hazard function $\left(h_{0}(t)=\gamma p t^{p-1}\right)$ indicates the presence of constant positive duration dependence ( $p$ is statistically equal to 2), which means that the probability of a housing boom ending at time $t$, given that it lasted until that period, increases over time but at a constant rate (Castro, 2010).

Regarding the economic determinants, we observe that when the growth rate of real GDP $(G D P)$ increases, the likelihood of a housing boom ending decreases. This means, as expected, that a good economic environment increases the length of housing booms. However, no significant effect is found on the duration of housing booms when the available credit $(\mathrm{Cred})$ grows. In fact, our results show that it is not the quantity of credit that matters, but its price. ${ }^{7}$ Considering the impact

\footnotetext{
${ }^{7}$ Interest rates can have both a direct and an indirect (via their effect on credit availability) impact on the dynamics of housing prices, thus, on the likelihood of housing price booms and busts (Agnello and Schucknecht, 2011; Taylor, 2007, 2009). Justiniano et al. (2015) argue that the housing boom that emerged before the Great Recession can be attributed to an expansion of credit supply and a relaxation of credit constraints in the mortgage sector. In contrast, Favara and Imbs (2015) point out that the impact of exogenous credit supply shocks on house prices depends on the elasticity of housing supply: when housing supply is elastic, it is the housing stock (not housing prices) that is more likely to respond to changes in credit market conditions. In this context, our result that the credit growth rate does
} 
of the interest rate $(\operatorname{LendIR})$, we observe that housing booms tend to be shorter when the interest rate rises. ${ }^{8}$ This means that the monetary authorities might play an important role in stabilizing the housing market, especially, when facing a boom. With these additional regressors in the model, our results also indicate that, on average, housing booms tend to be longer in the European than in the non-European countries. ${ }^{9}$ This statement is sustained by the marginally significant negative coefficient on European and, furthermore, by the estimates for each group of countries separately (Columns 2 and 3). The duration dependence coefficient is higher, in magnitude, when only the non-European countries are considered in the sample (Column 3), which indicates the greater propensity for housing booms ending over time in this group in comparison with the European countries - where the propensity is lower (Column 2). Another result to emphasize is the lack of significance of the coefficient on GDP in the regression for the non-European countries (Column 3), making the economic environment less relevant for the duration of housing booms in this group of countries, where the "price" of credit (interest rate) seems to play the most important role.

Finally, to avoid any influence from the recent financial crisis, we restricted the estimation to the period before 2008 (Column 4). The results of this analysis are not affected. In sum, we observe that the economic environment and the "price" of the credit are the most relevant factors impacting on the duration of housing booms and these tend to be longer in the European countries.

As the Weibull model is restrictive regarding the shape of the hazard function, ${ }^{10}$ the estimation of a more flexible specification may help to clarify potential doubts about its configuration. In this sense, a fully non-parametric piecewise or time-dummies specification (with a dummy variable for each year) might, in principle, allow for a free determination of the shape of the hazard function. However, according to Beck et al. (1998), one possible drawback of using dummy variables in these models is that the respective estimated hazard function is likely to "zig-zag" in time. ${ }^{11}$ Hence, the results may not be easily interpretable. The authors suggest using "natural cubic splines" to smooth out the coefficients of the hazard function. Therefore, we opt for this framework by including in the model a vector of spline basis variables that are cubic polynomials of $t$ (or Dur). Finally, we also note that, since the number of spline variables that is needed is much lower than the number of time-dummies, the statistical significance is easier to achieve and the time-dependence of the hazard function is straightforward to test.

The results with three cubic splines are presented in Columns 5-8. By comparing the estimates

not significantly affect the duration of housing booms suggests that policy instruments affecting credit supply (such as, reserve and liquidity requirements and limits on credit growth) have little or no detectable impact on the housing market.

${ }^{8}$ All the economic variables are lagged one period to avoid simultaneity problems and to account for the usual delays in the reporting of economic data.

${ }^{9}$ This result is consistent with the evidence found by Agnello et al (2015). In one hand, given that the real GDP growth and the lending rate are the significant determinants of the likelihood of housing booms' ending, this empirical finding reflects the fact that output growth has been, on average, stronger in European countries than in non-European countries, while borrowing constraints have been, on average, less tight in European countries than in non-European countries. On the other hand, it can also be linked with: (i) the differences in the financial structures and the fiscal policy framework (Berben et al., 2004); and (ii) the heterogeneity in the industry mix and the labour market rigidity (Georgiadis, 2012). All in all, these aspects can influence the response of macroeconomic variables to various sources of shocks, thus, shaping the duration of housing booms.

${ }^{10}$ In fact, it imposes that the hazard function can only rise or decline in a monotonic way.

${ }^{11}$ Additionally, since there is usually high multicollinearity among the dummy variables, individual coefficient estimates tend to have large standard errors. 
reported in Column 5 with those reported in Column 1, it can be seen that the coefficients of the covariates remain significant and have the expected signs. In this respect, our conclusions regarding the role of economic variables during booms remain qualitatively unchanged. We also note that the coefficients of the three cubic splines are highly significant, thereby, confirming that this Cloglog specification is a good framework to study the duration of housing booms and provides an accurate characterization of the likelihood of their ending after a certain duration. ${ }^{12}$ In particular, they show that the likelihood of a housing boom ending behaves in a nonlinear way: first, it increases at a steady pace; then, it slightly decreases for a while; finally, it increases again at a (much) faster pace after a substantial duration.

Additionally, in Columns 6 to 8, we report some regressions where the time-varying covariates are replaced with close proxies. For the economic environment, the GDP growth rate is replaced by the growth rate of the industrial production index $(I P)$. However, the coefficient associated with this variable is not significant, which may indicate that the higher volatility that characterizes it prevents it from unveiling the effects of the economic environment on the duration of housing booms. Therefore, we give preference to $G D P$ as a way of capturing those effects. Next, we use the ratio of domestic credit to GDP $($ CredGDP) instead of the growth rate of domestic credit as another way of controlling for the "quantity" effect of credit on the duration of housing booms. However, no relevant impact is found, which corroborates our conclusion that quantity effects are not the most important ones. As a last sensitivity analysis, we replace the lending interest rate by the money market interest rate $(M M I R)$, but the main results and conclusions remain unchanged: the "price" effect is indeed more relevant than the "quantity" effect.

\section{[INSERT TABLE 1 AROUND HERE]}

\subsection{Housing busts}

We now look at the evidence from housing busts (Table 2). Similarly to the case of housing booms, the results also point out to the presence of constant positive duration dependence, as $p$ is statistically greater than 1 and statistically equal to 2 , which means that the probability of a housing bust ending at time $t$, given that it lasted until that period, increases over time at a constant rate.

We observe that housing busts are mainly influenced by the economic environment: when the growth rate of real GDP $(G D P)$ increases, the likelihood of a housing bust ending decreases. No relevant impact is seen from the "quantity" (Cred) or the "price" (LendIR) effects. Such conclusions apply to the group of European countries (Column 2) which also seem to be more resilient to housing busts compared to the rest of the sample (the $p$ estimate is slighly larger than in the full sample case). Unfortunately, due to lack of data points, we cannot run the model for nonEuropean countries and, therefore, it is not possible to draw any conclusion about the differences in terms of the duration of housing busts between the two groups of countries. Focusing on the period

\footnotetext{
${ }^{12}$ The three spline-basis variables correspond to "knots" at terms 1, 30, 45 and 68, respectively. We chose this set of knots, because it produces statistically significant variables and the lowest $p$-value in terms of the rejection of the null hypothesis in likelihood ratio tests. A 3-knot solution (i.e. two cubic splines) was also tried, but the $A I C$, $S B I C$ and $L R I$ were lower. The results are available upon request. Hence, the model with three cubic splines is the preferred one.
} 
before the financial crisis of 2008-2009 does not affect the empirical findings (Column 3). Thus, we conclude that the duration of housing busts is only influenced by the economic environment: when it improves, housing busts tend to be shorter. This result is in accordance with the argument put forward by Leamer (2007) whereby although the housing sector is a relatively small component of GDP, the weakness of this sector is particularly dramatic during economic recessions.

Next, we provide the results for the flexible specifications of the hazard function using splines basis variables that are cubic polynomials of the respective duration variable (Dur). Columns 4-7 show that the cubic specification fits well to the data. In fact, all the three coefficients in the cubic polynomial specification are highly significant. ${ }^{13}$ The results also indicate that only the economic environment affects the duration of housing busts: the stronger the GDP growth rate $(G D P)$, the higher the likelihood of housing bust ending.

Finally, the additional sensitivity analysis where we replace the time-varying covariates with their close proxies shows that the conclusions are not significantly affected. The impact of the economic environment remains better captured by the GDP than by the $I P$; the alternative proxies to track the "quantity" and the "price" effects (CredGDP and MMIR, respectively) still display insignificant coefficients; and the three cubic splines remain highly significant. Furthermore, the coefficient on the dummy European is statistically significant, which is in line with the (weak) evidence from the basic model that, on average, housing busts are shorter in European countries.

\section{[INSERT TABLE 2 AROUND HERE]}

\subsection{Normal times}

Table 3 reports estimates of Cloglog duration model for normal times. The coefficient $p$ is not statistically different from 1 , which means normal times in the housing market are not duration dependent. The results also indicate that the duration of normal times is mainly affected by the economic environment (it is shorter when $G D P$ rises, as housing booms are more likely to occur) and these spells tend to be shorter in European countries. Furthermore, the results are not affected by the consideration of the period before the financial crisis of 2008-2009.

The empirical evidence remains unchanged after considering the flexible specification for the hazard function. The cubic splines indicate that the three coefficients are not statistically significant, thereby, confirming the absence of duration dependence. ${ }^{14}$

Regarding the economic determinants, all regressions confirm that only the economic environment significantly affects the duration of normal times in the housing market and these events are, on average, shorter for European countries.

\section{[INSERT TABLE 3 AROUND HERE]}

\section{Conclusions}

Using data for 20 industrialized countries over the period 1970Q1-2012Q2, we assess the characteristics of the various phases of the housing market cycles (housing booms, housing busts and

\footnotetext{
${ }^{13}$ The three spline-basis variables correspond to "knots" at terms 1, 30, 45 and 85, respectively.

${ }^{14}$ The three spline-basis variables correspond to "knots" at terms 1, 35, 60 and 107, respectively.
} 
normal times) and their main determinants, with a focus on the economic activity and the credit market conditions. Relying on a discrete-time Weibull duration model, we find evidence suggesting that, as time goes by, the probability that such phases of the housing market cycle will end increases, i.e. corroborating the existence of positive duration dependence.

Conditioning the duration of the different phases of the housing market cycle on a set of macroeconomic variables, we find that the economic environment plays a major role: when economic activity improves, housing booms become longer and housing busts are shortened. For housing booms, we also observe that credit market conditions are important: an increase in the "price" of credit (i.e. the lending rate) is associated with shorter housing booms. In what concerns normal times, they seem to be largely driven by the general economic activity.

In the same vein, our results show that while housing booms have similar length in European and non-European countries, housing busts are typically shorter in European countries. Moreover, our conclusions remain qualitatively unchanged when we relax the assumption regarding the shape of the hazard function and consider a more flexible cubic-splines specification.

From a policy perspective, our study provides information that can be useful for predicting the timing and the length of housing boom-bust cycles. This, in turn, helps designing and implementing stabilizing policies, in particular, given the likely impact of the housing market dynamics on real economic activity and the stability of the financial system. Additionally, given that interest rates can significantly reduce the length of housing booms, our empirical evidence corroborates the idea that "leaning against the wind" (monetary) policies can help to stabilize the housing sector, namely, by avoiding the occurrence of periods of prolonged housing price appreciation. Similarly, in the light of the strong impact of real output growth in terms of shortening housing bust spells, our results suggest that highlight the importance of growth-enhancing policies at promoting the rebound of housing prices from protracted slumps. Moreover, by characterizing the properties of the various stages of the housing cycles and presenting their similarities and differences across groups of countries, it contributes for a better understanding of the degree of synchronization of housing prices around the world. Finally, in the light of the role played by credit market conditions in the duration of housing booms, our study highlights the importance of the conduct of monetary policy, namely, by influencing lending rates and preventing such type of phases of the housing market cycle.

\section{References}

[1] Agnello, L., Castro, V., Sousa, R.M., 2012. How does fiscal policy react to wealth composition and asset prices? Journal of Macroeconomics, 34(3), 874-890.

[2] Agnello, L., Castro, V., Sousa, R.M., 2013. What determines the duration of a fiscal consolidation program? Journal of International Money and Finance, 37, 113-134.

[3] Agnello, L., Castro, V., Sousa, R.M., 2015. Booms, busts and normal times in the housing market. Journal of Business $\&$ Economic Statistics, 33(1), 25-45.

[4] Agnello, L., Schuknecht, L., 2011. Booms and busts in housing markets: Determinants and implications. Journal of Housing Economics, 20(3), 171-190. 
[5] Allison, P., 1982. Discrete-time methods for the analysis of event histories. Sociological Methodology, 13, 61-98.

[6] Arghyrou, M.G., 2009. Monetary policy before and after the euro: evidence from Greece. Empirical Economics, 36(3), 621-643.

[7] Arghyrou, M.G., Tsoukalas, J.D., 2011. The Greek debt crisis: Likely causes, mechanics and outcomes. The World Economy, 34(2), 173-191.

[8] Beck, N., Katz, J., Tucker, R., 1998. Taking time seriously: Time-series-cross-section analysis with a binary dependent variable. American Journal of Political Science, 42, 1260-1288.

[9] Berben, R.-P., Locarno, A., Morgan, J., Valles, J., 2004. Cross-country differences in monetary policy transmission. European Central Bank, ECB Working Paper No. 400.

[10] Castro, V., 2010 The duration of economic expansions and recessions: More than duration dependence. Journal of Macroeconomics, 32, 347-365.

[11] Castro, V., 2011. Can central banks' monetary policy be described by a linear (augmented) Taylor rule or by a nonlinear rule? Journal of Financial Stability, 27(4), 228-246.

[12] Castro, V., 2013. The duration of business cycle expansions and contractions: Are there changepoints in duration dependence? Empirical Economics, 44(2), 511-544.

[13] Castro, V., Sousa, R.M., 2012. How do central banks react to wealth composition and asset prices? Economic Modelling, 29(3), 641-653.

[14] Favara, G., Imbs, J., 2015. Credit supply and the price of housing. American Economic Review, 105(3), 958-992.

[15] Georgiadis, G., 2012. Towards an explanation of cross-country asymmetries in monetary transmission. Deutsche Bundesbank, Working Paper No. 7.

[16] Glaeser, E.L, Gottlieb, J.D., Gyourko, J., 2010. Can cheap credit explain the housing bubble? National Bureau of Economic Research, NBER Working Paper No. 16230.

[17] Hwang, M., Quigley, J., 2006. Economic fundamentals in local housing markets: Evidence from US metropolitan regions. Journal of Regional Science, 46(3), 425-453.

[18] Jawadi F., 2008. Does nonlinear econometrics confirm the macroeconomic models of consumption? Economics Bulletin, 5(17), 1-11.

[19] Jawadi, F., Léoni, P., 2012. Nonlinearity, cyclicity and persistence in consumption and income relationships: Research in honor of Melvin J. Hinich. Macroeconomic Dynamics, 16(S3), 376393.

[20] Jenkins, S., 1995. Easy estimation methods for discrete-time duration models. Oxford Bulletin of Economics and Statistics, 57, 129-138.

[21] Justiniano, A., Primiceri, G.E., Tambalotti, A., 2015. Credit supply and the housing boom. National Bureau of Economic Research, NBER Working Paper No. 20874.

[22] Leamer, E.L., 2007. Housing is the business cycle. Proceedings - Economic Policy Symposium - Jackson Hole, Federal Reserve Bank of Kansas City, 149-233.

[23] Mallick, S.K., Mohsin, M., 2010. On the real effects of inflation in open economies: theory and empirics. Empirical Economics, 39(3), 643-673. 
[24] Payne, J. E., Zuehlke, T. W., 2006. Duration dependence in real estate investment trusts. Applied Financial Economics, 16(5), 413-423.

[25] Prentice, R., Gloeckler, L., 1978. Regression analysis of grouped survival data with application to the breast cancer data. Biometrics, 34, 57-67.

[26] Poterba, J., 1984. Tax subsidies to owner-occupied housing: An asset-market approach. Quarterly Journal of Economics, 99(4), 729-752.

[27] Rothman, P., 1996. International evidence on business-cycle nonlinearity. In: Barnett, W.A., Kirman, A.P., Salmon, M., Eds. Nonlinear Dynamics and Econometrics. Proceedings of the Tenth International Symposium in Economic Theory and Economerics. Cambridge University Press, 333-341.

[28] Rothman, P., 1999. Nonlinear time series analysis of economic and financial data. Kluwer Academic Press.

[29] Rothman, P., 2006. Comments on 'structural change in macroeconomic time series'. Journal of Macroeconomics, 28, 151-153.

[30] Sousa, R.M., 2010a. Housing wealth, financial wealth, money demand and policy rule: Evidence from the euro area. The North American Journal of Economics and Finance, 21(1), 88-105.

[31] Sousa, R.M., 2010b. Consumption, (dis)aggregate wealth and asset returns. Journal of Empirical Finance, 17(4), 606-622.

[32] Taylor, J.B., 2007. Housing and monetary policy. Housing, housing finance and monetary policy. Federal Reserve Bank of Kansas City, Jackson Hole Symposium, 463-476.

[33] Taylor, J.B., 2009. Economic policy and the financial crisis: An empirical analysis of what went wrong. Critical Review: A Journal of Politics and Society, 21(2-3), 341-364.

[34] Zuehlke, T. W., 1987. Duration dependence in the housing market. Review of Economics and Statistics, 69(4), 701-709.

[35] Zuehlke, T. W., 2003. Business cycle duration dependence reconsidered. Journal of Business and Economic Statistics, 21(4), 564-569.

[36] Zuehlke, T. W., 2013. Estimation and testing of nonproportional Weibull hazard models. Applied Economics, 45(15), 2059-2066. 


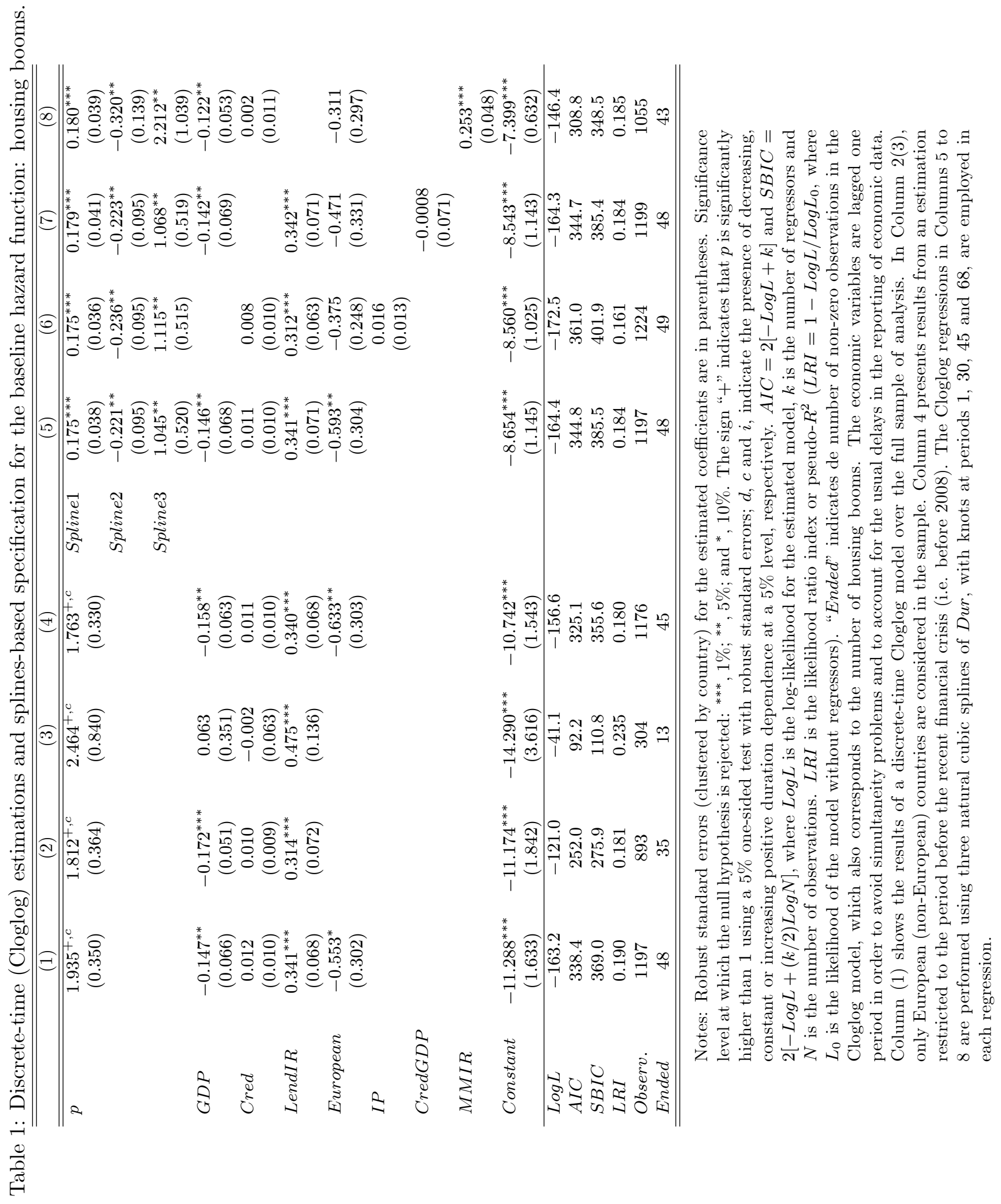




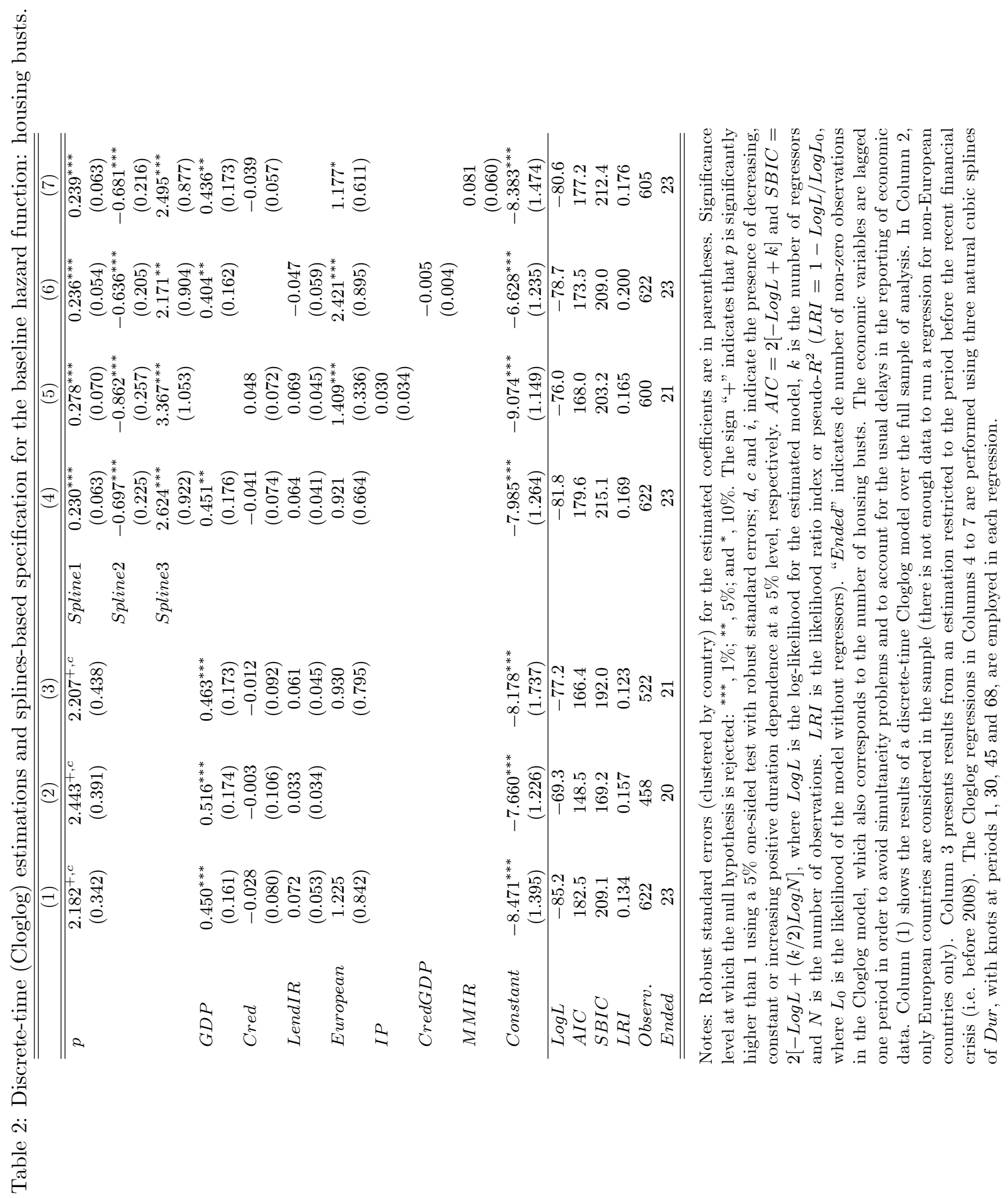




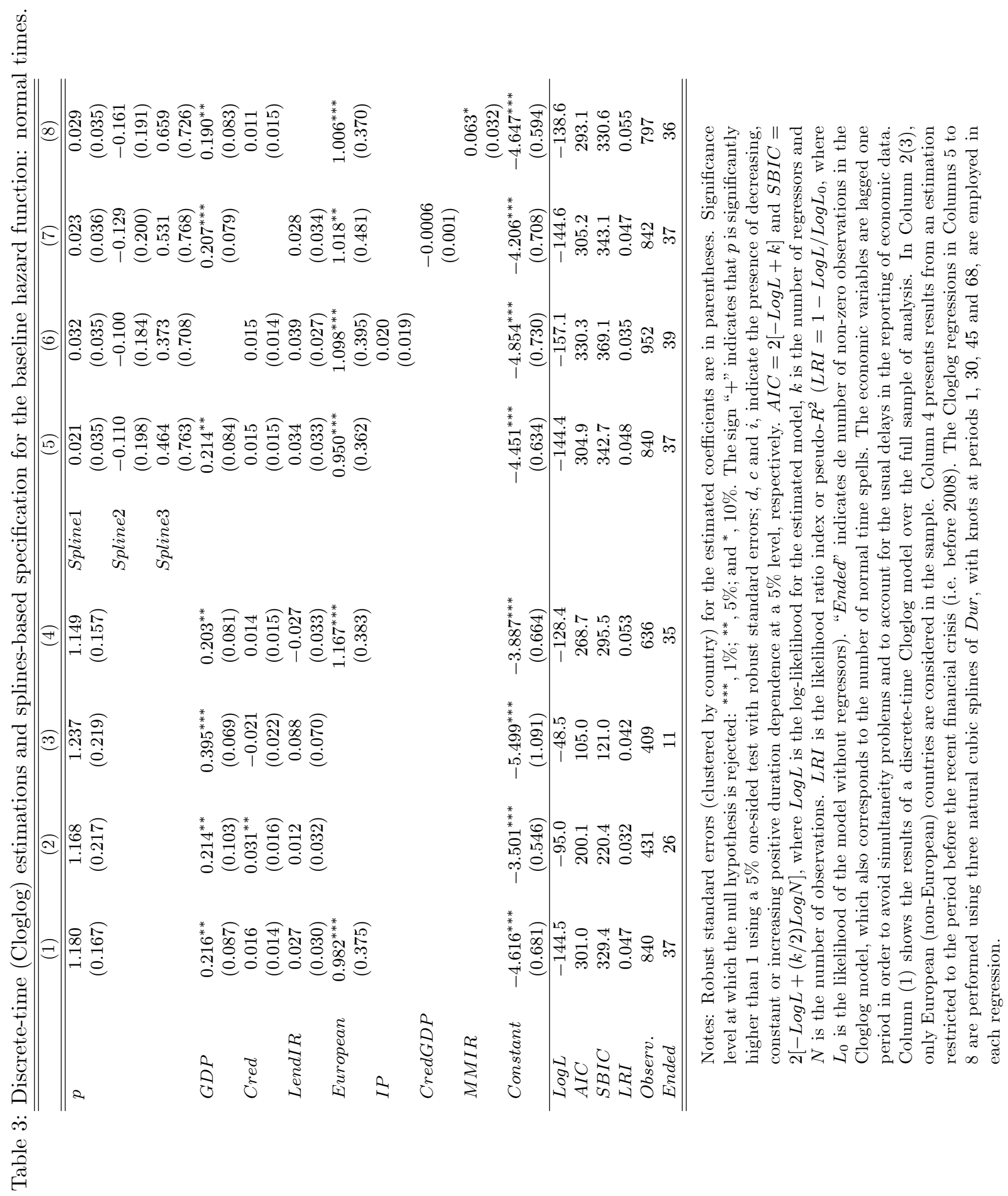

